\title{
TERRENOS PROTEROZÓICOS NA PROVÍNCIA BORBOREMA E A MARGEM NORTE DO GRÁTON SÃO FRANCISCO
}

\author{
EMANUEL F. JARDIM DE SÁ*, MARIA H.E MACEDO*, REINHARDT A. FUCK** e KOJI KAWASHITA***
}

\begin{abstract}
PROTEROZOIC TERRANES IN THE BORBOREMA PROVINCE AND THE NORTHERN MARGIN OFTHESÄOFRANCISCOCRATON. The northern inargm of the São Francisco craton is defined by major Brasiliano south verging thrust tod nappe structures. In the inner part of the Sergipano belt, recognition of allocthonous blocks and arc-type petronic assemblages allow us to envisage possible Brasiliano cycle suture zones. Indie Riacho do Ponud belt, reappraisal of field relations and new geochnological data confirm a Neoproterozoic age for the nappe structures, with the most external ones overlying the autocthonous Mesoproterozoic; cover rocks of the craton. In the northern part of tins belt, early Brasiliano accretion of a Mesoproterozoicterrane is postulated to have occurred along a transcunent suture. Further north, well inside the Boiborema Province, the Brasiliano Cycle is characterized by transcurreat/transpresstve deformation associated with crast-and mantle-derived phttonism, besides an ensialic, monocyclic supracrustal belt at Orós. In the Seridó belt (and in few other places) these structures rework a flat-lying Transamazonian fabric related to a southward thrusting regime. On the other hand, Mesoproterozoic units (and pre-Brasiliano thrusts?) are present south of the Patos shear zone. Evidence so far available allows the recognition of major blocks with contrasting tectonic evolution, possibly bounded by suture zone. The prominence of Brasiliano strike-slip kinematics leads us to speculate that transcurrent/transform terrane accretion was important during that event Alternatively, me presence of older thrusting regimes may record different periods of amalgamation of continental blocks, building up a heterogeneous litbosphere in die Borborema Province during Proterozoic times.
\end{abstract}

Keywords: Proterozoic terranes, Brasiliano orogeny, pre-Brasiliano structures, geochronological evolution, Borborema: Protetozok tetnoies, Province, Sao Francisco Craton, Northeast Brazil.

\begin{abstract}
RESUMO A margem norte do Cráton São é definida por extensos emporrões e nappes transportados para sul. Na parte interna da Faixa Sergipana, o reconhecimento de blocos alóctones e associações petrotectônicas de arco permite visualizar possíveis zonas de sutura do Ciclo Brasiliano. Na Faixa Riacho do Pontal, reavaliação das relações de campo e novos dados geocronologicos confirmam a idade neoproterozóica das estruturas de nappe, sendo que as mais externas cavalgam a cobertura mesopioterozóica autóctone do cráton. Na porção norte dessa faia, postulase a acresção cedo-brasfliana de um terreno mesoproterozóico, aokmgodeumasuturatranscorrente.Maisanorte,no ulterior da Provfhcia Borborema, o Ciclo Brasiliano é caracterizado por deformação transcorrente/transpressiva associada a volumoso plutonismo de origem crustal e mantélica, além de uma faixa supra crustral monocíclica,ensiálica, em Orós. Na Faixa Seridó (e em outros locais), essas estruturas retrabalham um fabric tangencial transamazônico, relacionado a um regime de empurrões para sul. Por outro lado, unidades mesoproterozóicas (e empurrões prébrasílianos?) estio presentes a sul da zona de cisalhamento de Patos. As evidências disponívmatéomomento permitem reconhecer grandes blocos crustais com evolução tectônica contrastante, provavelmente delimitados por zonas de sutura. A proeminência da cinemática transcorrente brasiliana conduz a especulações sobre a importância da acresção transcorrente/transformante de terrenos, durante aquele evento. Alternativamente, a presença de regimes de empurrões mais antigos pode significar o registro de diferentes períodos de amalgamação de blocos continentais, construindo uma litosfera continental heterogênea na Província Borborema, durante os tempos proterozóicos.
\end{abstract}

Palavras-chaves: Terrenos proterozóicos, Orogênese Brasiliana, estruturas pré-brasilianas, evolução geocronológica, Província Borborema, Cráton São Francisco, Nordeste do Brasil.

INTRODUÇÃO A noção clássica de uma extensa região geossinclinal neopcoterozóica na Província Borborema (PB), deformada durante o Ciclo Brasiliano, foi postulada nos trabalhos de Almeida (1967,1977), Almeida et al $(1976,1977)$ e Brito Neves $(1975,1978)$. Nesse contexto, os seus limites com o Cráton São Francisco (CSF) foram visualizados como sistemas de empurrões com vergência para o cráton.

Nos anos subseqüentes, investigações estruturais e radiométricas conduziram a questionamentos sobre o papel do Ciclo Brasiliano na PB, como gerador ou retrabalhando diferentes faixas supracrastais. Nessa linha, buscou-se distinguir faixas com evolução inonocícUca brasiliana (tendo como representante mais típico a Faixa Sergipana), daquelas com registro de estruturas de um ciclo prévio. Uma série de argumentos conduziu ã proposição de uma evolução policíclica transamazônicabrasiliana para a Faixa Seridó e seqüências julgadas correlacionadas (Jardim de Sá 1984, 1988, Jardim de Sá et al 1987, 1988, 1990), enquanto outros autores defendem um modelo de evolução monocíclica brasiliana (Caby \& Arthaud
1986, Caby 1989, Caby et al. 1991, Archanjo \& Bouchez 1991).

Ao invés de uma solução mais simples, intermediária ou favorecedora de uma das hipóteses acima, o estudo continuado do problema e o acúmulo de dados trouxeram à tona um quadro bem mais complexo, no qual novas questões estão se sobrepondo à polarização "monocíclico vs. policíclico" dos anos precedentes. Algumas dessas questões serão abordadas neste trabalho, incluindo os argumentos que sugerem a aglutinação de terrenos geológicos distintos durante a evolução geodinâmica daPB.

Por outro lado, a abordagem estrutural, com ênfase na cinemática da deformação, junto com novas datações e revisão do quadro estratígráfico, voltam a fortalecer o modelo clássico de um frvnt de empurrões e nappes brasilianos para o limite norte do CSF.

\section{O LIMITE NORTE DO CRÁTON SÃO FRANCISCO AO LONGO DA FAIXA SERGIPANA A interpretação aqui}

\footnotetext{
* Departamento de Geologia, Universidade Federal do Rio Grande do Norte, Campos Universitário, Caixa Postal 1639, CEP 59072-970, Natal, RN, Brasil ** Instituto de Geociencias, Universidade de Brasilia, Campus Asa Norte, CEP 70910-900, Brasflia, DF, Brasil *** Centro de Pesquisas Geocronológicas, Instituto de Geociências, Universidade de São Paulo, Caixa Postal 20899, Cep 01498-970, São Paulo, Sp, Brasil
} 
esboçada é baseada nas contribuições de Silva et al. (1978), Jardim de Sá et al. (1986a), Campos \& Brito Neves (1987) e Davison \& Santos (1989), junto com dados obtidos no âmbito de projetos do PLGB (DNPM/CPRM) e pesquisas recentes da UFRN na região de Canindé do São Francisco e adjacências (Bezerra et al 1991, 1992, Bezerra 1992).

A porção sul da Faixa Sergipana (FS), correspondendo à sedimentação de margem passiva dos Grupos Estância/Miaba/Vaza Barris (Fig. 1), mostra uma evolução cinemática simples, dominada por um fabric preponderante refletindo transporte para sul. Metassedimentos de baixo grau e dobrados com trend WNW são empurrados sobre a cobertura cratônica correlata. No setor NW da FS, os nappes externos da faixa são transportados para sul por cerca de 30 - $40 \mathrm{~km}$ sobre 0 cristalino autóctone do cráton (região de Curaçá, BA). Nesse setor ainda se nota o funcionamento sincrônico de transcorrências dextrais, enquanto as estruturas WNW da região de Simão Dias (SE) são sinistrais e tardias com respeito ao transporte para sul. Davison \& Santos (1989) reconheceram estruturas extensionais sin-sedimentares, localmente preservadas da inversão brasiliana.

Deformação polifásica, mas também dominada por transporte para sul, acompanhada de metamorfismo de fácies xisto verde a anfibolito, caracterizam a faixa do Grupo Macururé mais a norte (Fig. 1). Esses metassedimentos correspondem a depósitos turbiditicos, em parte de margem passiva (sugerido pelos contatos gradacionais com os quartzitos basais da Formação Santa Cruz), dominando todavia uma associação flyschóide (presenç̧a de intercalações ou detritos vulcânicos, olistostromas). E importante registrar que, em direção norte, lineações de estiramento indicam a ocorrência de movimentos oblíquos ou longitudinais à faixa.

Embora um rejeito importante esteja envolvido no empurrão que delimita o Grupo Macururé a sul, faltam argumentos mais seguros para interpretá-lo como um terreno distinto com respeito aos Grupos Miaba/Vaza Barris; litotipos similares são observados em ambos (mesmo que em proporções diferentes), e o seqüenciamento de fácies e estruturas é "normal" no contexto da faixa. $\mathrm{O}$ aumento do grau metamórfico para norte, associado a igual mergulho das foliações (com atitudes suaves, quando não afetadas por deformação superposta), é compatível com a ocorrência de metamorfismo inverso e estruturas de nappes, com deslocamentos pluriquilométricos.

A porção norte da FS mostra grande complexidade. É possível propor ou especular sobre a justaposição de terrenos com apreciável aloctonia (Davison \& Santos 1989), ou caracterizados pela acresção de crosta juvenil neoproterozóica. Este último é o caso do Terreno Canindé do São Francisco, interpretado como uma seqüência tipo arco insular/bacia pós-arco (Jardim de Sá et al 1986a, Bezerra et al. 1991,1992), provavelmente instalada adjacente a uma placa continental (ou terreno) a norte, correspondente ao "Maciço Pernambuco-Alagoas". O Terreno Marancó, embora de caracterização menos precisa, pode representar um bloco alóctone independente (é interessante investigar, nesse contexto, o significado das ultramáficas cromitíferas ali presentes), ou um pequeno fragmento desmembrado do Maciço Pernambuco-Alagoas quando da implantação da Seqüência de Arco do Terreno Canindé. Finalmente, assinala-se que o Maciço Pernambuco-Alagoas é intrudido por volumosos batólitos granitóides brasilianos ao longo de sua margem meridional, em sua maior parte encaixados em unidades pré-brasilianas de alto grau metamórfico.

A sequiência de eventos cinemáticos é correspondentemente complexa. Relidos de um fabric envolvendo transporte para sul, em alto ângulo com o trend da faixa, são detectados no Terreno Canindê, bem como no Grupo Macururé na região de Arapiraca. Movimentos oblíquos ou longitudinais são todavia a expressão dominante na estruturação dessas seqüências a norte. O contato sul do Terreno Marancó com o Grupo Macururé é feito por um empurrão oblíquo (para SE), com espessas faixas miloníticas que afetam granitoides brasilianos. $\mathrm{Na}$ porção mais setentrional do Grupo Macururé em Alagoas, transporte tangencial para WNW é sucedido por retroempurrôes e dobramentos com vergência para norte. Transcorrência sinistrai na borda sul do Terreno Canindé e a sul do antiforme de Jirau do Ponciano pode materializar urna zona de compensação (transferência) entre esses movimentos longitudinais diferenciais. Movimento do Maciço Pernambuco-Alagoas para SE, na porção ocidental da faixa, é sugerido pela transcorrência dextral (antigo empurrão reativado como rampa lateral?) ao longo do seu contato com o Grupo Macururé.

Não existem dados em contrário à interpretação de que as estruturas descritas são todas relacionadas com a evolução do Ciclo Brasiliano. Isto é sugerido pela isócrona $\mathrm{Rb}$-Sr do granito de Poço Redondo (a SE de Canindé do São Francisco, $600 \pm 23$ Ma; Davison \& Santos 1989), a nosso ver produzido por fusão crustal (do Terreno Marancó) induzida no seu cavalgamento pela Seqüência de Arco Canindé. Outras datações disponíveis ca. 630 Ma para o granito tardi-tectônico de Cel. João Sá, BA, (isó crona Rr-Sr reportada por Santos \& Souza 1988, com dados posteriormente reavaliados por W. Teixeira, com. verbal), por exemplo, corroboram com esse quadro.

Fatias de embasamento, preservando bem suas estruturas antigas, mas com faixas miloníticas retrometamórficas brasilianas, estão envolvidas na deformação de empurrões e transcorrências na porção sul da FS, sendo facilmente identificadas na região de Simão Dias e Itabaiana. Próximo a Jirau do Ponciano, o contato basal do quartzito Santa Cruz também marca uma antiga superfície de não-conformidade, agora extensivamente retrabalhada. No embasamento dessa região, granitóides datados em 2,5 Ga (isócrona Rb-Sr, M.H.F. Macedo e colab., dados inéd.) são tardios em relação aos eventos pré-FS, e mostram-se extensivamente afetados pela deformação longitudinal da faixa ("transcorrência sinistrai", no caso). Na porção mais a norte da FS, a separação do embasamento com respeito às supracrustais de alto grau é mais difícil, mas $\mid x n$ fabric antigo é reconhecível em algumas unidades gnáissicas por meio de critérios estruturais e de seu truncamento por diques de anfibolito (Jardim de Sá \& Calheiros 1981). No setor NW da FS (região de Cabrobó), o embasamento a norte registra um evento $c a$. 1,1-1,0 Ga, conforme indicado pelos dados radiométricos de Lima et al. (1986, ver também Gava \& Uma 1986), o que conduz a considerar o Maciço Pernambuco-Alagoas como um bloco complexo.

A integração desses dados (Fig. 1) leva a interpretar convergência com subducção para norte na porção setentrional da FS, incluindo acresção de um terreno de arco (e outros blocos alóctones?), com posicionamento final transcorrente. Um modelo de escoamento longitudinal de blocos, combinado a retroempurrões, parece representar melhor a deformação sin a tardi-colisional nessa porção da FS. No setor meridional, sucessivos empurrões em direção ao CȘF finalizam com o posicionamento de nappes e transcorrências subordinadas.

\section{O LIMITE NORTE DO CRÁTON SÃO FRANCISCO AO} LONGO DAFAIXARIACHO DO PONTAL O conceito original de uma faixa marginal brasiliana nesta região, com supracrustais neoproterozoicas (Brito Neves 1975,1978, Almeida et al 1976,1977, Almeida 1977, Santos \& Caldasso 1978), foi posteriormente contestado por alguns autores com base na interpretação de que os micaxistos do Complexo Casa Nova seriam mais antigos que a cobertura mesoproterozóica (Supergrupo Espinhaço) do CSF (Souza et al. 1979, Mascaranhas 1979, Jardim de Sá \& Hackspacher 1980). Os resultados de mapeamento na região de Sobradinho, reportados por Jardim de Sá \& Souza (1989) e Souza \& Jardim de Sá (1989), foram julgados favoráveis a esse modelo, distinguindo uma seqüência quartzítica autóctone (integrante do Complexo 


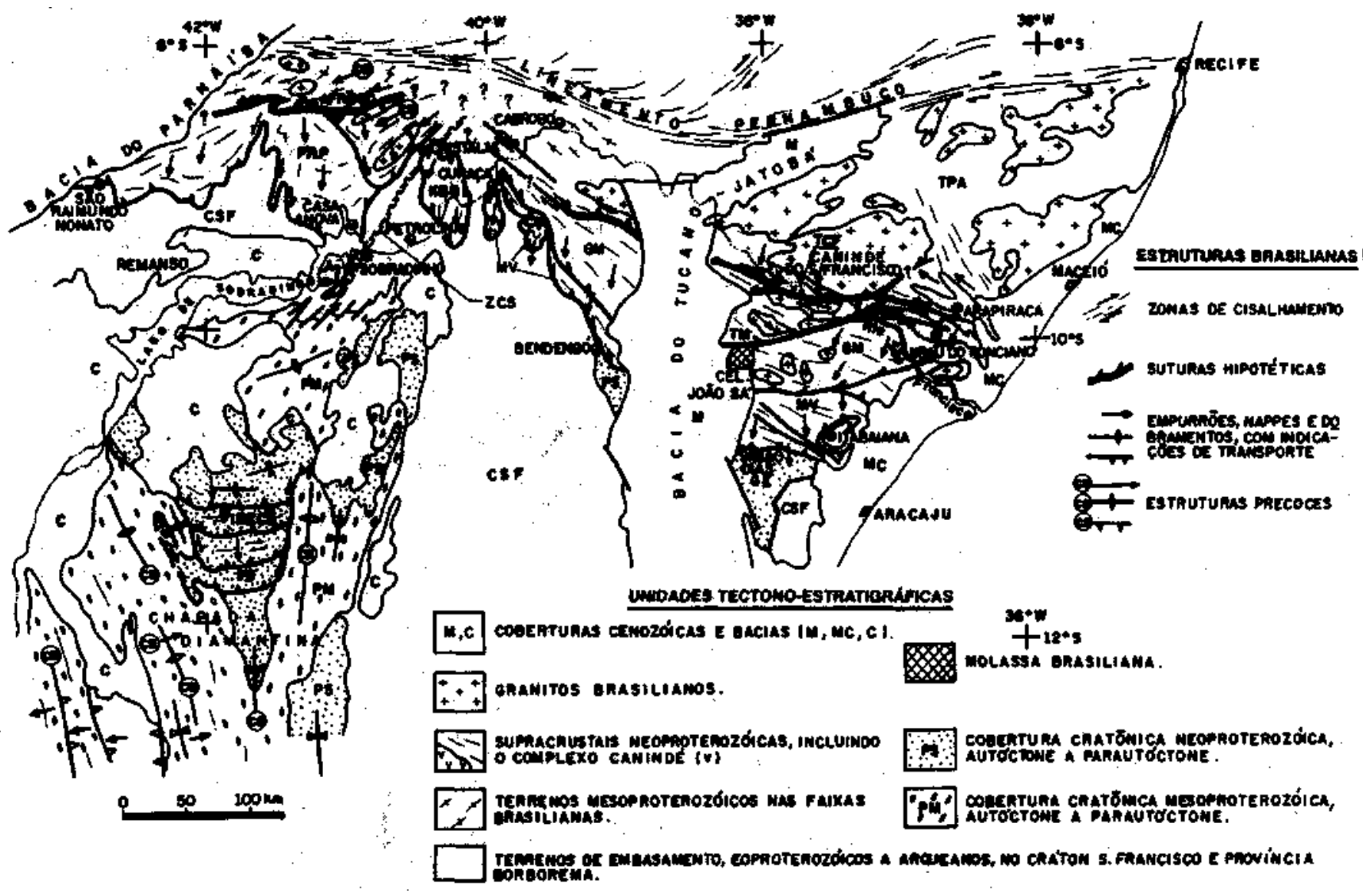

Figura 1 - Esboço tectônico da margem norte do Cráton São Francisco (CSF). Abreviaturas: GE. Grupo Estância; MV. Grupo Miaba/Vaza Barris; GM. Grupo Macururé; TM. Terreno Marancó; TCF. Terreno Canindé do São Francisco; TPA. "Maciço (Terreno) Pernambuco-Alagoas"; FRP. Faixa Riacho do Pontal; KBB. Klippe de Barra Bonita

Figure 1 - Tectonic framework of the northern margin of the Sã o Francisco craton

Casa Nova) e seu embasamento arqueano, cavalgados por um nappe de micaxistos transportado para sul, todo o conjunto sendo capeado em não-conformídade pela Formação Tombador (Proterozóico Médio). Nesses termos, a tectônica de nappes foi atribuída ao Ciclo Transamazônico. Argumentos adicionais provinham do redobramento do nappe num padrão escalonado compatível com transcorrência dextral ao longo da Zona de Cisalhamento de Sobradinho, de trend NE (Jardim de Sá \& Souza 1989, Souza \& Jardim de Sá 1989, Fig. 2A). A norte do Rio São Francisco, a zona de cisalhamento controla o posicionamento de granitos porfiríticos sincinemátícos, com fabric magmátíco e dúctil também transcorrente dextral, e datados (isócronas Rb-Sr) em $2000 \pm 107 \mathrm{Ma}$ (localidade Riacho do Sobrado, a norte de Sobradinho; Jardim de Sá et al. 1988) e 1848 + 19 Ma (Cristália; Mendes \& Silva 1989). Para sul, a zona de cisalhamento é nitidamente capeada pela Formação Tombador.

A avaliação mais recente desse quadro favorece a hipótese de idade brasiliana para a deformação tangencial do Complexo Casa Nova (Fig. 2). Numa das localidades da suposta discordância basal do Proterozóico Médio, a oeste de Sobradinho, BA (Fig. 2B), verificou-se que o quartzito micáceo subjacente (até então interpretado como o autóctone do Complexo Casa Nova) é parte de uma seqüência supracrustal mais antiga (aqui referida como Complexo Sobradinho), datada do Arqueano Superior, com base em isócrona $\mathrm{Rb}-\mathrm{Sr}$ de $2,6 \mathrm{Ga}$, obtida em granito epizonal intrusive na mesma (M.H.E Macedo e colab., dados inéd.). Os trabalhos de campo não conseguiram comprovar a ocorrência de um "quartzito Casa Nova" capeado em discordância pela Formação Tombador. Tal fato reforça a idéia de que o "quartzito Casa Nova" antes mapeado
(Souza et al 1979, Jardim de Sá \& Souza 1989) corresponda a uma fácies deformada da própria Formacão Tombador, já que suas feições sedimentológicas parecem similares (em especial, a presença de fácies eólicos; Vila Mônaco, comunicação verbal). Neste caso, o nappe de micaxistos suprajacente poderia ser de idade neoproterozóica, como sugerido pelas datações adiante comentadas.

Forte evidência em favor de uma idade pós-transamazônica para os nappes foi recentemente obtida na região de Cristália, no prolongamento para norte da zona de cisalhamento de Sobradinho (Fig. 2C). A interpretação inicial de que aquela estrutura trancaria o klippe de Barra Bonita (Jardim de Sá et al. 1988, Mendes \& Silva 1989) é preterida em favor da hipótese de uma idade mais antiga para aquela zona de cisalhamento, com posterior reativação. Na Fazenda Prazeres (leste de Cristália), foi descoberto um metaconglomerado polimicto (autóctone a parautóctone) sotoposto ao nappe, com fragmentos do granito porfirítico (transarnazônico) adjacente, previamente deformados em relação à matriz do metaconglomerado. E interessante observar que, nessa área, a foliação da zona de cisalhamento tem baixo ângulo de mergulho para NW, analogamente à foliação local do nappe. Todavia, os critérios cinemáticos no granito confirmam movimento dextral na superficie inclinada (resultando em, "topo para NE"), enquanto o nappe foi transportado para sul. E interessante registrar que os granitos miloníticos apresentam um retrabalhamento retro rnetamórfico sinistrai, o que pode ser devido ao aproveitamento da zona de cisalhamento antiga como uma rampa lateral dos nappes.

Retomada a hipótese original de evolução brasiliana para a Faixa Riacho do Pontal (FRP), sua organização litotectônica 

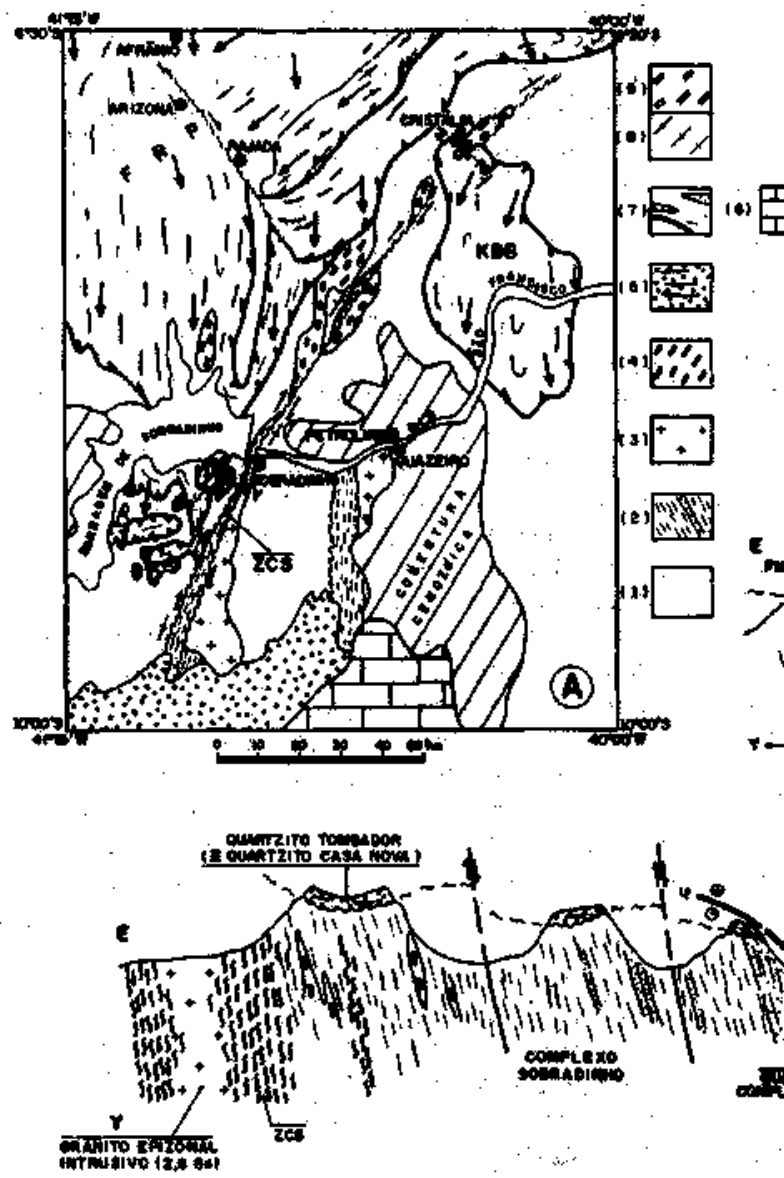

(B)
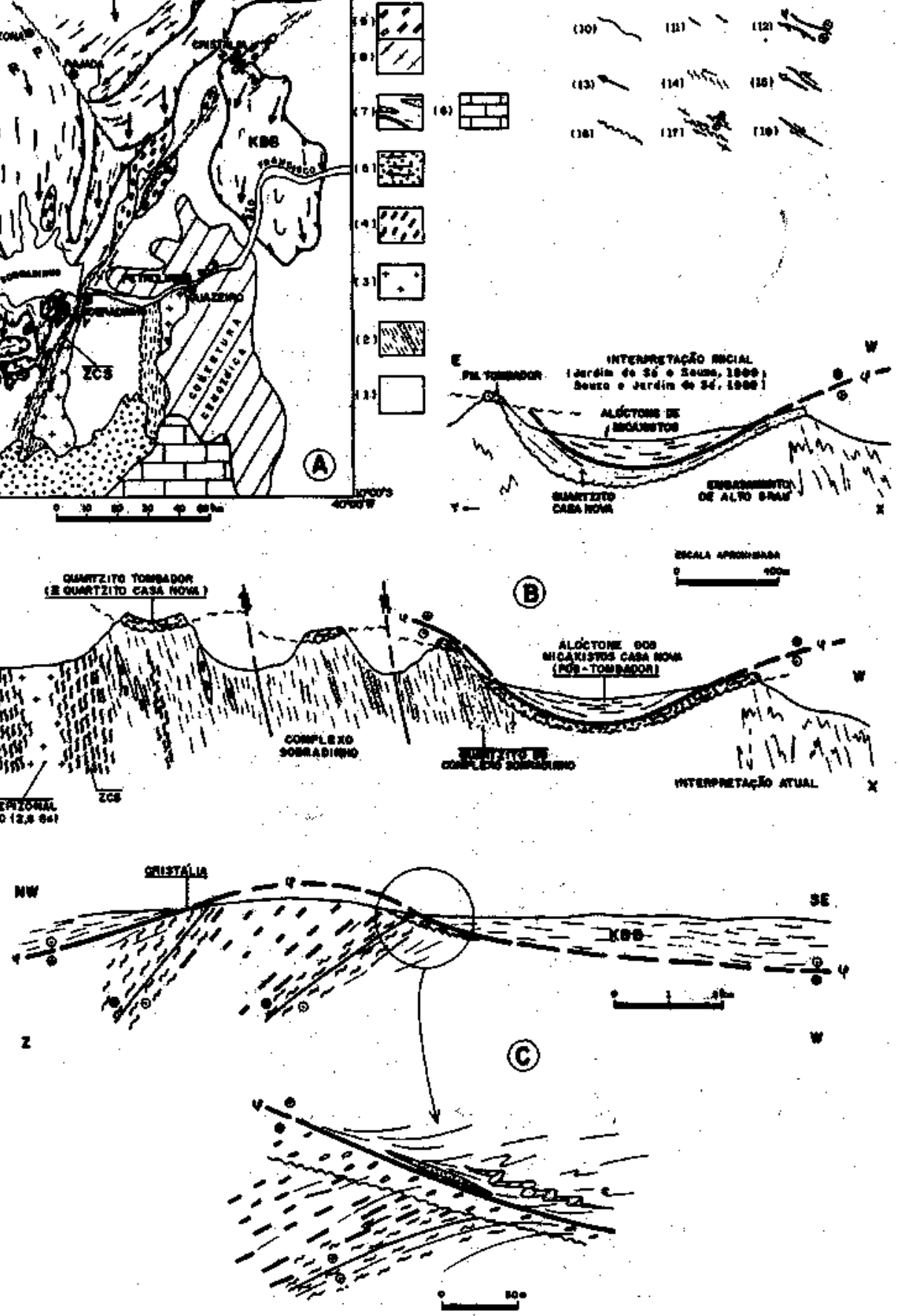

Figura 2 - Relações estruturais e estratigráficas na margem sul da Faixa Riacho do Pontal (FRP). A. Mapa geológico simplificado. Simbolos e abreviaturas: 1. gnaisses de alto grau arqueanos; 2. supracrustais de baixo grau arqueanas; 3. granitos arqueanos; 4. granitos transamazônicos sin-ZCS; 5. Supergmpo Espinhaço (Formação Tombador); 6. Grupo Una; 7. Complexo Casa Nova; micaxistos com lentes de mármore equartziío, e metaconglomerado sotoposto ao irappe; 8. granitos brasilianos (tipo Rajada); 9. granitos e quartzo sienitos alcalinos brasilianos (tipo Serra da Alegria); 10. contatos geológicos; 11 . trends de foliação brasiliana; 12. nappes brcisilianos (rnapa e seção,- nesta lUíma o símboh indica bloco si 'rior "aproximando-se" do observador); 13. transporte tangential brasiliano; 14. rampa lateral/obliqua brasiliana; 15. transporte tangential e empurrões oblíquos cedobrasilianos; 16. discordância na base do Proterozóico Médio; 17. zona de cisalhamento transcorrente transamazônica, mapa (incluindo mergulho da foliação) e perfil; 18. falha normal pós-brasifiana. B. Relações entre os nappes, a Formação Tombador do Proterozóico Médio, e a transcorrência transamazônica (ZCS), a oeste de Sobradinho (perfil XY). Explicações no texto, mesma legenda anterior. C. Relações entre os nappes (Iclippe de Barra Bonita, KBB) e os granitos e transcorrência (ZCS) transamazônicos (perfil WZ). Explicações no texto, mesma legenda anterior

Figure 2 - Stractural and stratigrafic ralations in the southrern margin of the riacho do Pontal fold belt (FRP). A. Simplified geological map. B. Relations between the nappes, ttae Middle Froterozok cover and die Transamazonian shear zone (ZCS). \& Rdatíonsbips between the nappes (Bana Bonita klippe, KBB) and transamazonian granites and shear zone (ZCS) 
pode ser descrita, na porção meridional, por dois ou mais nappes de micaxistos, provavelmente constituídos, em sua maior parte, por ftyschóides neoproterozóicos. Esses nappes teriam cavalgado os gnaisses arqueanos e granitos transamazônicos, com o mais externo deles alcançando a borda norte da cobertura mesoproterozóica do CSF, representada pela Formação Tombador. Deslocamentos da ordem de 30 a $60 \mathrm{~km}$ parecem estar implicados. Mais a oeste, o Complexo Colomi tem um comportamento alóctone semelhante, possivelmente de mesma idade. Por outro lado, a tectônica de empurrões com transporte para sul, recentemente caracterizada na região de Irecê, BA (Lagoeiro \& Alkmin 1991), deve representar um efeito distai dessa compressão brasiliana, conferindo um caráter parautóctone à cobertura neoproterozóica do CSF (o Grupo Una).

Através da FRP, o aumento do grau metamórfico para norte (regular até Afrânio, PE) e o mergulho dos planos de foliação no mesmo sentido (quando não dobrados por evento subseqüente) são mais uma vez compatíveis com metamorfismo inverso num contexto de nappes. A evolução retrometamórfica e 0 efeito de cobertor termal do alóctone foram bem caracterizados a SW de Sobradinho, BA (Souza \& Jardim de Sá 1989). O nappe mais externo mostra transporte para S/SSE, e a datacão de $555 \pm 10 \mathrm{Ma}$ (isócrona $\mathrm{Rb}-\mathrm{Sr}$ com $\mathrm{Ro}=0,7068 \pm$ 0,$002 ;$ M.H.F. Macedo e colab., dados inéd.) para os granitos e quartzo sienitos alcalinos, sin a tardi-cinemáticos, a NW de Sobradinho (Serra da Alegria), marca a idade mínima desse evento.

Em um nappe mais interno (Rajada) e na porção norte do nappe externo, o evento com transporte para sul está superimposto a um episódio com movimento tangencial para WSW/SW, muito bem marcado nos ortognaisses Rajada, interpretados como fusões crustais sintectônicas (granitóides com duas micas). Essas rochas foram datadas em $539 \pm 25 \mathrm{Ma}$ (Rajada, isó crona Rb-Sr, Santos \& Silva 1990) e 743 $\pm 59 \mathrm{Ma}$ (localidade de Dormentes, a ENE de Afrânio, isócrona Rb-Sr, Jardim de Sá et al. 1988). Consideramos a primeira datacão como uma cifra mínima, já que o Sienito Caboclo, corpo tardi a pós-tectônico a NE de Afrânio, forneceu uma isócrona $\mathrm{Rb}-\mathrm{Sr}$ de $634 \pm 8 \mathrm{Ma}$ (DNPM/CPRM, dados inéd.). Uma isócrona composta com as amostras dos Ortognaisses de Rajada e Dormentes fornece um resultado de $667 \pm 10 \mathrm{Ma}$, considerado como uma estimativa aceitável para esse primeiro episódio cinemático.

Na região a norte de Afrânio, afloram metassedimentos também afetados pela deformação com transporte tangencial para SW, mas agora guardando evidências de um evento mais antigo com direção de transporte N-S (e predomínio aparente de indicações de movimento para norte). Vários corpos de augen gnaisses intrudem esses metassedimentos, exibindo a lineação de estíramento N-S. Uma isócrona Rb-Sr (Jardim de Sá et al. 1988) e recente datação U-Pb em zircão (J. Leterrier e colab., dados inéd.) confirmam uma idade $c a$. 1,0 Ga para um desses corpos. Desta forma, esse bloco norte provavelmente representa um terreno mesoproterozóico, justaposto à FRP durante a orogênese brasiliana (mais especificamente, durante 0 evento com transporte longitudinal à faixa). As Seqüências de Monte Horebe/Brejo Seco (Angelim 1988, Gomes 1990) podem fazer parte desse terreno mais antigo ou mais provavelmente representam depósitos de arco magmático (metavulcânicas máficas com quimismo de toleítos pobres em $\mathrm{K}$, metagrauvacas vulcanogênicas com intercalações tufáceas, metocherts; quartzitos) aprisionados numa "sutura transcorrente" delimitando esses diferentes terrenos. Gnaisses migmatíticos intercalam-se nesse contexto e podem constituir um embasamento para os metassedimentos mesoproterozóicos. Em direção a norte, zonas de cisalhamento transcorrentes dextrais, correlatas ao Lineamento Pernambuco, retrabalham as estruturas anteriores e devem corresponder, no tempo, aos empurrões com transporte para sul. A PORÇÃ O CENTRAL DA PROVÍNCIA BORBO-
REMA: ACRESCAO DE TERRENOS OU UMA
LITOSFERA, CONTINENTAL UNICA DURANTE O
PROTEROZÓICO? Se a Província Borborema (PB) envolvia um segmento litosférico continental único e contínuo durante o Proterozóico, isto demandaria uma natureza ensiálica para as faixas supracrustais no seu interior e/ou o retrabaIhamento de crosta continental gerada em evento(s) termotectônico(s) pré-brasiliano(s).

As investigações desenvolvidas nesse amplo setor (norte do Lineamento Pernambuco, até a porç̃o central do Ceará) têm conduzido à interpretação de que o Ciclo Brasiliano caracterizou-se pelo estabelecimento (ou a simples deformação?) de uma faixa com feičões ensiálicas (caso da Faixa Orós, vide adiante), pela adição de magmas juvenis (provavelmente mais significativos na crosta inferior) e, especialmente, pelo retrabalhamento de unidades e terrenos mais antigos, incluindo a geração de frações importantes de fusões crustais. Todavia, tais feições são insuficientes para assegurar a continuidade da litosfera continental, em tempos brasilianos ou antes deles. Ao contrário, começam a surgir evidências que são compatíveis com uma litosfera continental formada por blocos distintos (terrenos suspeitos ou alóctónes?), sendo que a amalgamação desses blocos pode ter sido efetuada durante o Ciclo Brasiliano, e/ou creditada a evento(s) pré-brasilianos(s).

No setor considerado, um exemplo de faixa monocíclica brasiliana é a de Orós, incluindo sua extensão longitudinal à região de Pio $\mathrm{DC}$ (SW do Ceará), e prováveis seqüências correlatas na região limítrofe CE-RN (Jaguaribe - São Miguel). Jardim de Sá et al. (1988,1991 - ver também Jardim de Sá et al. 1986b) caracterizam nessa faixa um regime de transcorrência/transpressão dextral, acompanhado de metamorfismo de fácies xisto verde a anfibolito de pressões baixas (Orós) a intermediárias (Oeste do Rio Grande do Norte). Datações U-Pb em zircão e $\mathrm{Rb}-\mathrm{Sr}$, reportadas por aqueles autores (idem Macedo et al. 1988) em rochas metavulcânicas e granitos da região de Orós ( $c a \cdot 1,8-1,7 \mathrm{Ga}$ ), revelam que a deposição da seqüência supracrustal naquele setor foi condicionada por um ambiente extensional implantado logo após o clímax do Ciclo Transamazônico. Isto é corroborado pelas afinidades geoquímicas dos produtos magmátícos, que evoluem de tipos shoshoníticos a alcalinos intraplaca (Sá 1991). Por outro lado, existe a possibilidade de que os turbiditos do topo da coluna representem depósitos ftyschóides neoproterozóicos, conforme sugerido no modelo de evolução monocíclica arguido por Caby (1989).

No setor delimitado entre a região central do Ceará e o Lineamento Pernambuco, o Ciclo Brasiliano tem a sua melhor expressão no plutonismo granitóide contemporâneo (rochas sintectônicas têm fornecido isócronas $\mathrm{Rb}-\mathrm{Sr}$ na faixa entre 670 e $550 \mathrm{Ma}$ ) ao sistema de cisalhamentos transcorrentes e zonas transpressivas, com predominância de cinemática dextral (Jardim de Sá et al. 1986c, 1987, Sial 1986,1987, Arthaud et al 1988, Torquato et al. 1989, Leterrier et al. 1990, Caby et al 1991). Assumindo o funcionamento sincrônico das zonas E-W (Lineamentos Patos e Pernambuco) e NE (como a Faixa Sendo), Corsini et al (1991) explicam a transpressão nos segmentos NE como um efeito de borda de blocos cujo deslocamento principal é comandado pelos lineamentos E-W. Um padrão complexo.com movimentos dextrais e sinistrais, está presente a sul do Lineamento Patos. Também ocorrem setores em que a foliação associada às zonas transcorrentes exibe baixo angulo de mergulho, compondo leques transpressivos e estruturas em flor (Arthaud et al. 1988, Archanjo \& Bouchez 1991). Todavia, não existe comprovação radiométrica, neste setor da PB, de extensas regiões com deformação brasiliana em regime de empurrões.

A maior parte das rochas granitóides brasilianas (tipos I francamente predominantes sobre tipos $S$ e A) é de derivação crustal, conforme sua assinatura isotópica de $\mathrm{Sr}$ e $\mathrm{Nd}$, com 
freqüente caráter subalcalino (monzonítico)/cálcio-alcalino potássico. Magmas mantélicos são registrados em volume subordinado (séries shoshoníticas diferenciadas de gabros, dioritos potássicosetiposfélsicos)(TorquatOtfiaí, 1989, Leterrier et al. 1990, Galindo et al. 1991). Dados de gravimetria regional (Moreira et al. 1989) são compatíveis com significativa adição de corpos básico-intermedianos à crosta inferior, provavelmente correspondendo aos dioritos potássicos dessas suítes brasilianas. Na Faixa Salgueiro-Cachoeirinha, é interessante registrar a abundância de rochas alcalinasperalcalinas sin/tardi-brasilianas (Ferreira \& Sial 1986, Sial \& Ferreira 1988, Silva \& Guimarães 1990, Guimarães \& Silva 1990).

O metamorfismo brasiliano é, em geral, de pressões baixas e varia da fácies xisto verde a anfibolito, com visível associação aos maciços granitóides e zonas de cisalhamento (Legrand \& Jardinde Sá 1986, Uma 1987, Jardim de Sá et al 1987, Corsini et al. 1991).

Ainda no setor referido, as investigações geocronológicas realizadas até o momento não comprovam a ocorrência de rochas supracrustais neoproterozóicas. No caso da Faixa Sendo, os metassedimentos (incluindo a sequência turbidítica ftyschóides no topo da coluna) são intrudidos por granitóides (os ortognaisses "G2") datados em 2,0 -1,9 Ga (dados Rb-Sr e U-Pb, Macedo et al. 1984 e dados inéd., Jardim de Sá et al 1987,1988, Legrand et al 1991); idades modelo Sm-Nd de rochas metavulcânicas máficas intercaladas nos turbiditos flyschóides também confirmam sua deposição no Proterozóico Inferior (Macedo et al. 1990).

Novas datações questionam a continuidade para sul da Faixa Seridó e sua correlação às Unidades Salgueiro-Cachoeirinha, conforme aceito nos trabalhos clássicos (Brito Neves 1975,1978, Almeida rt o/. 1976,1977) e sínteses subseqüentes (Santos \& Brito Neves 1984, Jardim de Sá 1984,1988, Jardim de Sá et al. 1987,1988,1990) sobre a província.

A oeste de Salgueiro (PE), ortognaisses datados em 2,0 Ga (M.H.F. Macedo e colab., dados inéd.) intrudem metassedimentos de faties anfibolito, mas seus contatos alóctones com as supracrustais de baixo grau, tradicionalmente referidas ao Grupo Cachoeirinha, dificultam estabelecer as relações originais entre essas unidades.

Por outro lado, datações no setor centro-oriental do Grupo Cachoeirinha demonstraram a presença de rochas metavulcânicas com idade U-Pb em zircão de $1117 \pm 83 \mathrm{Ma}$, e isócrona Rb-Sr de $950 \pm 7$ Ma (região de Manaíra, PB; Brito Neves et al. 1990), e ortognaisses intrusivos datados $c a, 1,0 \mathrm{Ga}$ (região de São José do Egito, dados Rb-Sr e U-Pb, Jardim de Sá et al. 1988, M.H.F. Macedo e colab., dados inéd.). Deve-se admitir, assim, a presença de rochas \pm eventos tectonometamórficos do Proterozóico Médio (1,1-1,0 Ga) e inferior ( $c$ a. 2,0 Ga) a sul do Lineamento Patos, contrastando com o arcabouço cronoestratigráfico aparentemente mais simples a norte, na Faixa Seridó (ver também Silva 1984).

A NW da Faixa Orós-Jaguaribe, na região central do Ceará, Caby \& Arthaud (1986) e Arthaud \& Hartmann (1986), propuseram a existência de nappes brasilianos, afetando supracrustais monocíclicas e o embasamento de alto grau arqueano. Essa interpretação comporta alguns problemas, já que dados $\mathrm{Rb}-\mathrm{Sr}$ preliminares (Pessoa et al, 1986) de leucogranitos peraluminosos sin a tardi-tectônicos em Pedra Branca sugerem que a deformação tangential naquela região pode estar relacionada ao Ciclo Transamazônico. Além das transcorrências brasilianas (Arthaud 1986, Arthaud et al 1988), existem registros de dois vetores cinemáticos com idade relativa e absoluta ainda incerta, marcando movimentos tangenciais para oeste e para sul (Arthaud \& Hartmann 1986), um dos quais poderia refletir o Ciclo Transamazônico.

Esses eventos/seqüências de idade pré-brasiliana, provável ou comprovada, representam um elemento chave para o esclarecimento da evolução geodinâmica da Província Borborema
(PB). Um dos pontos de conflito é a interpretação, como intrusões sinorogênkas, dos ortognaisses datados em 2,0-1,9 Ga (no Sendo e oeste de Salgueiro) e ca. 1,0 Ga (São José do Egito e Afrânio, este último na Faixa Riacho do Pontal). No Sendo, esses plútons marcam um evento de deformação tangencial com transporte para sul (e neste caso com idade ca. 2,0 - 1,9 Ga), incluindo a deposição de turbiditos ftyschóides num estágio precoce (Jardim de Sá \& Barbalho 1991). Em outras regiões, as interpretações são menos seguras. $\mathrm{Na}$ porção oriental da Faixa Salgueiro-Cachoeirinha, os ortognaisses $c a$. 1,0 Ga registram transporte tangencial para W/NW, sendo ainda duvidoso atribuir tal deformação àquela idade ou ao Ciclo Brasiliano. A oeste de Salgueiro (região de Parnamirim, PE), um regime tangencial com transporte para NW/WSW está impresso tanto em augen gnaisses de 2,0 Ga como nos metassedimentos de baixo grau tradicionalmente de eventos distintos com cinemática similar, seja a presença de seqüências de baixo grau com idades distintas, nas porções oeste e centro-leste daquela faixa.

A conotação de suítes orogênicas atribuída aos ortognaisses acima citados (Jardim de Sá et al. 1988) é apoiada por relações de campo (analogia aos fabrics magmático e tectônico, indicando posicionamento num contexto de deformação tangencial; presença de auréolas de contato dinâmicas; intrusões pegmatíticas correlatas, plano-axiais a dobramentos recumbentes etc.) e dados geocronológicos (datações Rb-Sr indicativas de um evento tectonometamórfico contemporâneo nas encaixantes, sejam gnaisses do embasamento - Macedo et al 1984, sejam rochas supracrustais - Brito Neves et al 1990), com suporte adicional nos estudos geoquímicos preliminares dessas suítes (Jardim de Sá \& Leterrier 1990, Medeiros et aí. 1991). Obviamente, esta interpretação implica num contexto policíclico para as metaplutônicas e supracrustais encaixantes. A figura 3 incorpora essa interpretação de unidades policíclicas.

A interpretação alternativa aventada por Caby (1989, ver também Caby et al. 1991), de intrusões anorogênicas em seqüências platafomiais/intracratônicas, poderia ser melhor aplicada à Faixa Orós (Sá et al 1988,1991, Sá 1991), sendo este ponto retomado adiante. Em tal caso, toda a deformação registrada naquelas seqüências e suítes com idade entre 2,0 a 1,7 Ga seria atribuível ao Ciclo Brasiliano. Excetuando-se o caso da região de Orós acima referida, a hipótese de intrusões anorogênicas para as demais suítes 6 contrariada pela ausência de fades vulcânicas associadas, pela natureza ftyschóide de boa parte das seqüências encaixantes, pela distinção geoquímica com respeito a séries tipicamente anorogênicas e pela contemporaneidade entre termos cálcioalcalinos (embora aparentemente subordinados) e os augen gnaisses dominantes, de composição subalcalina/cálcio-alcafina potássica.

Mesmo tipificadas como suítes de afinidade orogênica, subsistem algumas dúvidas sobre a sua contemporaneidade em relação à intensa deformação tangencial (e metamorfismo de fades xisto verde a anfibolito) que afeta, em cada setor, as intrusões e suas encaixantes. Desse modo, visualiza-se a alternativa de que esses terrenos pré-brasilianos fariam parte de faixas orogênicas intracontinentais (dominância de rochas subalcalinas em relação a termos cálcio-alcalinos mais típicos), com deformação moderada (ausência de eventos colisionais) e preservadas em nível crustal elevado. No Ciclo Brasiliano, forte deformação tangencial (provavelmente na forma de eventos discretos, pouco espaçados no tempo e sucedidos por um regime de transcorrênda) obliteraria a quase totalidade da história deformacional pré-brasliana. Esta variante da interpretação policíclica deve continuar a ser confrontada com os dados presentemente em obtenção; em especial, a datação de rochas sintectónicas (p.ex., sheets pegmatíticos) e de eventos metamórflcos. 
Alan das feições cronoestratigráficas e deformacionais (vetores cinemáticos) contrastantes entre as faixas supracrustais (ou parte das mesmas), a idade do embasamento de alto grau (e provavelmente, a idade crustal) pode diferir entre setores distintos da PB. Suítes TTG de idade arqueana (2,7-2,5 Ga) ocorrem na região central do Ceará (Pessoa et al. 1986), a sul de São José do Egito na Faixa Salgueiro-Cachoeirinha (Wanderley 1990), em Jirau do Ponciano na Faixa Sergipana (M.H.F. Macedo e colab., inéd.), e outros. Por outro lado, os ortognaisses Caicó na Faixa Sendo, antes tidos como arqueanos, constituem suítes cálcio-alcalinas de origem mantélica (Martin et al. 1990), com idade entre 2,23 e 2,15 Ga (dados U-Pb, Rb-Sr e Pb/Pb; Hackspacher et al. 1990, Macedo et al. 1991, Dantas et al. 1991, Legrand et al 1991).

Os dados sumarizados são sugestivos de que, ao invés de uma litosfera continental contínua, a PB é bastante heterogênea e se compõe de terrenos (ou domínios, subprovíncias etc.) de evolução distinta sempre apresentando retrabalhamento e acresção magmática brasiliana (Fig. 3).

\section{DISCUSSÃO: HAVERIAM SUTURAS PROTEROZÓI- CAS NA PROVÍNCIA BORBOREMA? QUAL Ó CONTEXTO GEODINAMICO DOS TERRENOS PRE- BRASILIANOS NA PROVÍNCIA BORBOREMA? \\ Com uma estrutura melhor caracterizada pelos trabalhos de detalhe desenvolvidos no continente africano, podemos regis- trar que a zona de sutura pan-africana, localizada a leste do Cráton Oeste Africano, deve se prolongar no Brasil, encoberta pelos sedimentos da Bacia do Parnaíba (Trompette 1979, Caby et al. 1981, 1991, Caby 1987, 1989, Lesquer et al 1984, Jardim de Sá 1984, Jardim de Sá et al. 1987,1990). Os eventos deformacionais mais diretamente correlacionáveis a esse limite são aqueles observados no NW do Ceará - transcorrências e transporte tangencial para SW (Abreu et al 1988, Gama et al 1990), envolvendo tanto as supracrustais do Grupo Martinópole ( \pm Grupo Ubajara), como gnaisses e granulitos mais antigos, datados ca. 1,9 Ga pelo método Rb-Sr (Abreu \& Lafon 1991).}

Por outro lado, a caracterização de seqüências magmáticas de arco, na região de Canindé dó São Francisco (Bezerra et al. 1991, 1992), permite visualizar um processo de colisão e suturamento na porção norte da Faixa Sergipana, ainda que os segmentos de litosfera oceânica envolvidos tenham sido de expressão provavelmente reduzida. Os dados graviméricos disponíveis (Rand et al 1980, Santos \& Souza 1988) são compatíveis com o espessamento crustal requerido, mas demandam detalhamento para uma precisão melhor do quadro. Na Faixa Riacho do Pontal (FRP), a atuação de processos de subducção/ colisão é mais especulativa; todavia, uma faixa de anomalias Bouguer positivas, na continuidade para SW da FRP (vide Mascarenhas \& Sá 1982, p.ex.), pode eventualmente demarcar uma sutura, e sua extensão para leste corresponderia à região de Afrânio (PE).

No tocante à porção central da Província Borborema, uma série mais volumosa de questões se apresenta. Qual o significado da tectônica transcorrente, que tem inclusive extensa continuidade na África? Seriam de fenômenos de escoamento lateral (escape tectôniço), tardios à colisão dos escudos do Hoggar/ Nigéria/Borborema com o Cráton Oeste Africano/São Luís (Caby et al.; 1981, Jardim de Sá 1984)? Ou ô reflexo de convergência fortemente oblíqua dessas placas (Boullier 1982)? Ou ambos os fenômenos, contínuos no tempo?

Se o processo de aglutinação dê terrenos se deu durante o Ciclo Brasiliano, envolvendo movimentos transcorrentes/transformantes, jpelo menos algumas Üàs ${ }^{1}$ grandes zonas de cisalhamento na PB são candidatas potenciais a representarem zonaszonas de sutura $(\mathrm{Hg}, 3)$. Nesses termos, zonas de cisalhamento separando setores com geologia/ geocronologia contrastantes,

associadas á anomalias gravimétricas demarcadas por corpos máfico-ultramáficos, senam os candidatos mais lógicos a re-

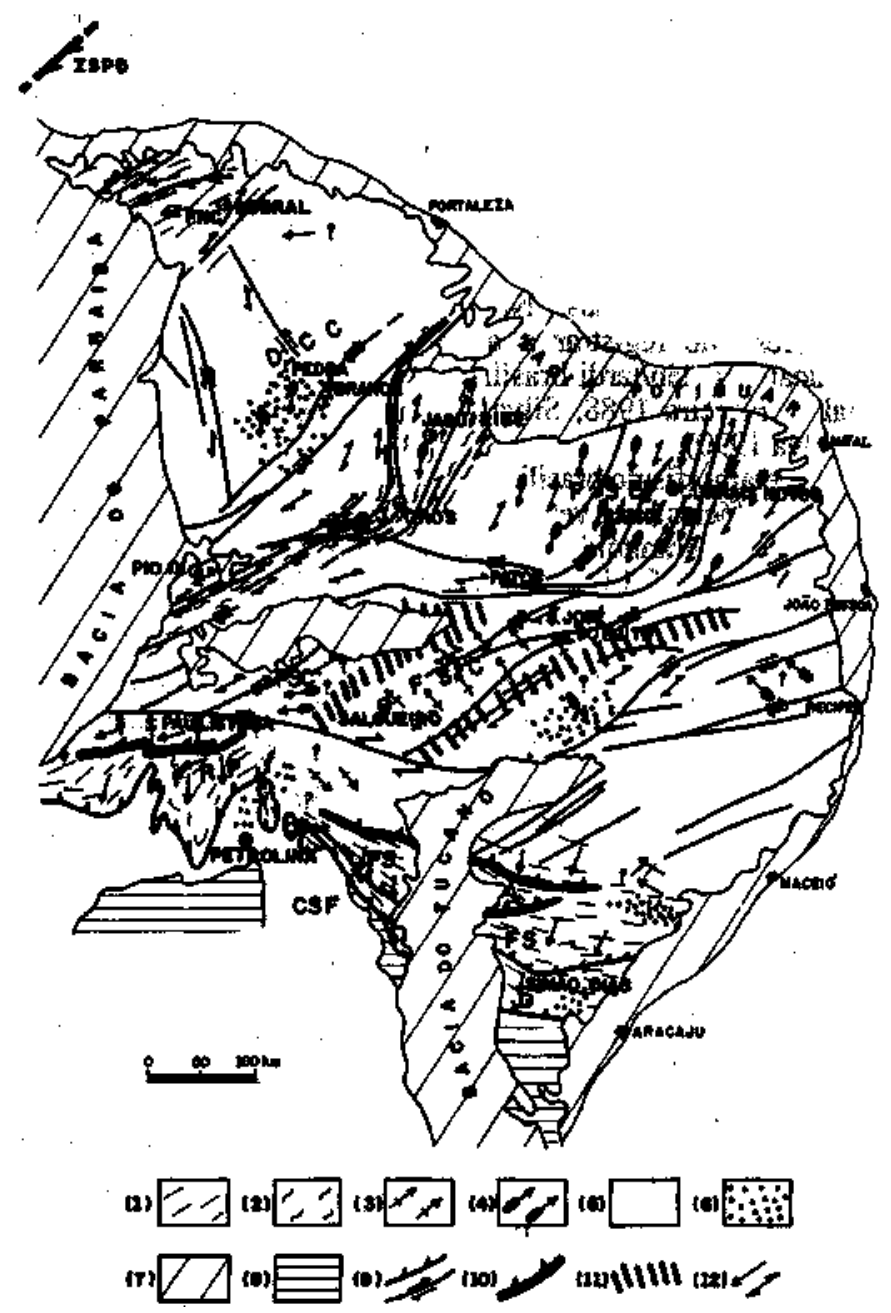

Figura 3 - Esboço tectônico da Província Borborema. Símbolos: 1. faixas monocíclicas (supracrustais neoproterozóicas dominantes) brasilianas, marginais aos crátons e exibindo zonas de suturas; 2. faixas monociclicas (supracrustais meso \pm neoproterozóicas) brasilianas, ensiálicas; 3. terrenos com unidades \pm eventos mesoproterozóicos, incluindo vetores de cinemática tangencial; 4. terrenos poticíclicos transamazônicos, incluindo vetores de cinematica tangencial; 5. embasamento de alto grau paleoproterozóico; 6. embasamento de alto grau arqueano; 7. cobertura fanerozóica; 8. cobertura proterozóica no CSF; 9. empurrões e transcorrências brasilianos; 10. suturas hipotéticas brasilianas; 11. zonas suspeitas para localização de outras suturas proterozóicas; 12. cinemática brasiliana, empurrões e transcorrendo. CSF. Cráton São Francisco; FS. Faixa Sergipana; FRP. Faixa Riacho do Pontal; FSC. Faixa Salgueiro-Cachoeirinha; FSE. Faixa Seridó; FOJ. Faixa Orós-Jaguaríbe; DCC. Domínio Central do Ceará; FNC. Faixa Noroeste do Ceará; ZSPD. zona de sutura Pharusiana/Dahomey (localização aproximada) Figure 3-Tectonic framework of the BorboremaProvince

presentarem zonas de sutura. É importante registrar, nesse sentido, a recente identificação de rochas máficas eclogíticas, como as descritas por Beurlen et al. (1990,1991), que poderiam ser marcadores dessas estruturas. Subsiste tambem a possibilidade de que o suturamento esteja relacionado a episódio(s) de tectônica tangencial, caso em que a incorporação de pelo menos alguns dos terrenos também poderia estar relacionada a evento(s) pré-brasiliano(s).

Sobre a história pré-brasiliana, parece haver uma certa continuidade evolutiva entre as suítes magmáticas datadas $c a$. 
2,0 -1,9 Ga (no Seridó, p.ex.) e aquelas na faixa 1,8 - 1,7 Ga, ditas "anorogênicas". Nesses termos, seqüências típo Orós podem ser interpretadas em relação a bacias extensionais tardi

a pós-orogênicas, que materializariam o colapso dá cadeia transamazônica (Bertrand \& Jardim de Sá 1990, Sá 1991). Igualmente no que toca às seqüencias de idade 1,2 - 1,0 Ga (Faixa Salgueiro-Cachoeirinha), resta definir se o atual nível crustal desses terrenos orogênicos já apresentava as feições de

intensa deformação tangencial \pm alto grau metamórfico em tempos pré-brasilianõs 0 *ipótese aqui favorecida), ou se então representavam faixasintrâcontinentais afetadas por processos

orogênicos de; pequena intensidade.

O conhecimento específico necessário à resolução dessas questões é ainda restrito em grandes extensões da Província Borborema, o que deixa margem a um elenco de possibilidades e a uma longa trilha para pesquisas.
Agradecimentos $\boldsymbol{O}$ s autores agradecem as discussões e cessão de dados junto a colegas da UFRN (J.M. Sá, F.H.R. Bezerra, Z.S. Souza, V.E. Amaro, L.C. Souza e V.P. Fonseca) e de outras instituições (J. Leterrier e J.M. Beitrand, CRPG Nancy; J J. Peucat e H. Martin, Rennes; A. Vauchez e R. Caby, Montpellier, B.B. Brito Neves, USP, M.H. Arthaud, UFCE). As pesquisas foram desenvolvidas com recursos de convênios FINEP/PADCT, CNPq, CAPES/COFECUB e Com. Econ. Européia. O presente trabalho foi apresentado em outubro de 1991

durante a Conferência de Campo "O Proterozóico Médio e Superior no Brasil", realizada em Morro do Chapéu (BA) sob patrocínio da SBG - Núcleo Bahia, CPRM e SGM - BA; os autores agradecem aos seus organizadores pelo honroso convi-

te para participação.

REFERÊNCrÀS BIBLIOGRÁFICAS

ABREU, FAM: GAMA, T., Ir; GORAYEB, PS.S.; HASU, Y, 1088 0 cinturfo de cisalhamento Noroeste do Ceard In: CONG AMER. GEOL. 7. Belém, 1988. Anais... Belém, SBG. p. 20.34

ABREU, F.A.M. \& LAFON, J.M. 1991. Granulitos transamazonicos no cinurfo de cisalhamento a norceste de Patos In: SIMP. GEOL. NORDESTE 14. Recife, 1991. Atas... Recife, SBG. p. 229-231.

ALMEIDA, F.FM. 1967. Origem e evoluçäo da Plataforma Brasileira. Rio de Janeiro, DNPM/DGM. 36 p. (Boletim 241).

ALMEIDA. F.F.M. 1977. O craton do Sæo Francisco. Rev. Bras. Geoc. $7(4): 349-364$.

ALMEIDA, FFM.; HASUI, Y.; BRITO NEVES, B.B. 1976. The upper Precambrian of South America. Bol. IG/USP, 7:45-80.

ALMEIDA, FFM.; HASUI, Y.; BRTTO NEVES, B.B.; FUCK, R. 1977 Provfncias estruturais brasileinas. In: SIMP. GEOL NÖRDESTE 8 Cam pina Grande, 1977. Atas. Recife, SBG. p. 363-391.

ANGELIM, L.A.A. 1988. PLGB, Santa Filomena, Folha SC.24-V-A.III, Texto e Mapas. Brasflia, DNPM/CPRM. 146 p.

ARCHANJO, C.J. \& BOUCHEZ, J.L. 1991. Le Serid6, une chaine transpressive dextre au Proterozoique superieur du Nort-Est du Bresil. Bull. Soc, Gtol France, 162(4):637.647.

ARTHAUD, M.H. 1986. A Falha de Taut (CE), zona de cisalhamento dictil de alto Angulo de rejeito múltiplo. In: CONGR. BRAS. GEOL., 34. Goiania, 1986. Anais... Goiânia, SBG. v. 2, p. 766-769.

ARTHAUD, M.H. \& HARTMANN, M.B. 1986. A geologin dn regiso de Independência (CE): um exemplo de tectânica de nappe no Ceart in: CONGR. BRAS. GEOL., 34. Goilnia, 1986. Anais... Goilnis, SAG. v. 3. p. $1160-1169$.

ARTHAUD, M.H.; NOGUEIRA NETO, J.A.; TORQUATO, IRF 1988. A zona de cisalhamento dúctil de Quixeramobim (CF) In:

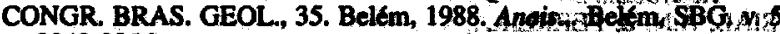
p. 2248-2256.

BERTRAND, J.M. \& JARDIM DE SA, E.F. $19 \%$ W Wed of the Ebomian-

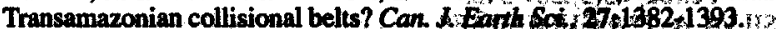

BEURLEN, H.; PESSOA, R.R.; ALMEIDA, CN - ALENC AR, SG. 1991.

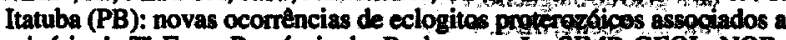

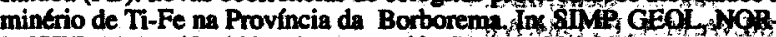
DESTE, 14. Recife, 1991. Atas... Recife, SBG p. $236-239$

BEURLEN, H.; SILVA, A. F; GUMARARS, I.P. SAMPAO AS; 1990 Evolução metamórfica dos eclogitos da ocomenang de $F$-TI de Fapend Boa Esperança, Bodoc6, Brasil. In: CONGR. BRAS GEO 36 Natal, 1990. Anais... Recife, SBG. v. 4, p. 2025-2039.

BEZERRA F.H.R. 1992. Geologia e Evolucdo Pernolórica doi Com Gabróico Caninde do Sato Francisco e Rochas Metavulanicas Adjacentes (Sergipe e Alagoas). Brasflia. 205 p. (Disserteflo de Mestrado, IG/UnB).

BEZERRA, F.H.R.; JARDIM DE SÁ, E.F.; NILSON, A.A.; BLAIS, S. 1992 $O$ ambiente tectónico do complexo Caninde do STo Francisco e mochas encaixantes - Faixa Sergipana, NEdo Brasil. In: SIMP. REG. GEOL BAHIA-SERGIPE, 1. Salvador, 1992. Atas... Salvador, SBG. p. 117-120.

BEZERRA, FH.R. NIL SON, A.A.; BLAIS, S.; JARDIM DE SA, E.F. 1991 Petroquímica de elementos maiores e tracos do complexo gabróico Canindé e sequencia metavulcanossedimentar encaixante (SE-AL). In: CONGR. BRAS. GEOQ., 3. Sżo Paulo, 1991. Anais... Sžo Paulo, SBGq v. 1, p. 181-184

BOULIIER A.M. 1982. Etude Structurale du Centre de l'Adrar des Iforas (Mali), Mylonites et Tectogenese. Nancy. 348 p. (These d'État, INPL).

BRITO NEVES, B.B. 1975. Regionalizafáo Geotectónica do Precambriano Nondestino. São Paulo. 198 p. (Tese de Doutoramento, IGUSP).

BRTTO NEVES, B.B. 1978. A propósito da evolucăo litoestratigrafica do Precambriano superior do Nondeste. J. Miner, 7:19-27. (V. Djalms Guimaries).
BRITO NEVES, B.B.; VAN SCFMUS, W.R.; BASEI, M.A.S. 1990. Contribuiç̨o an estudo da evoluctlo geocronológica do sistema de dobramentos Pianc6-Alto Brígida. In: CONGR. BRAS. GEOL., 36. Natal, 1990. Anais... Recife, SBG. v. 6, p. 2697-2710.

CABY, R. 1987. The pan-african belt of West Africa from the Sahara desert to the gulf of Benin. In: SCHAER, J.P. \& RODGERS, J. eds. The Anatomy of Mountain Ranges. Princeton, Princeton Univ. Press. p. 129-170.

CABY. R. 1989. Precambrian terranes of Benin-Nigeria and Northeast Brazil and the late Proterozoic south Aclantic fit. In: DALLMEYER, R.D. ed. Terranes in the Circum-Allantic Paleozoic Orogens. USA, Geol. Amer. Spec. Pap. 230, p. 145-158.

CABY, R. \& ARTHAUD, M.H. 1986. Major precambrian nappes of the Brazilian belk, Ceard, Northeast Brazil. Geology, 14:871-874.

CABY, R. BERTRAND, J.M.; BLACK, R 1981. Pan-African ocean closure and continental collision in the Hogear-Iforas segment, central Sahara. In: KRONFB A od Rrecambrian Plate Tectonics. Amsterdam, Elsevier. 0.49734

CABY, R., SIAL, A.N.; ARTḦAUD, M. VAUCHEZ, A. 1991. Crustal evoIntion and the Bonilianoromeny in Northeast Brazil. In: DALLMEYER,

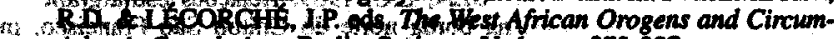

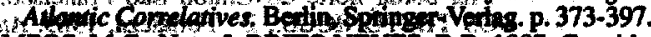

CAMPÓS, M.C., Neto \& BRTIO NEVES, B.B. 1987. Consideraçбes sobre a oronizaciae geometrin lasistema dedabrumentos Sergipano. In: SMMP.

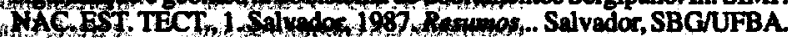
p. 0.93

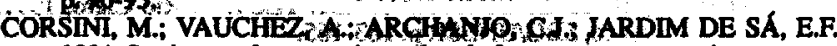

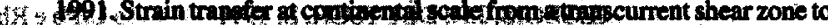

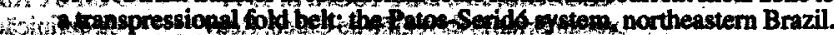

DANTAS, E.L.; HACKSPACIIIT RG, KAWASHITA, K; LAFON, J.M.

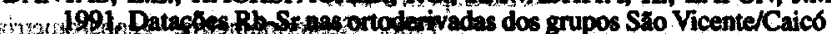

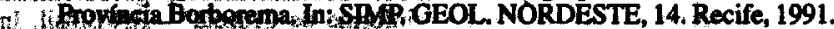
.

DAVISON, I. \& SANTOS, R.A. 1989. Tectonic evolution of the Sergipano wiril fold belt NE-Brazil, during the Brasiliano orogeny. Precamb. Res.

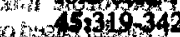

FERREIRA, V.P. \& SIAL A.N. 1986. The peralkalic magmatism in the TH precambrian Cachocirinha-Sal gueiro fold belt, Northeast Banail: geochemical aspocts. Rev. Bras. Geoc., 16(1):73-85.

GALINDO, A.C.; DALLAGNOL, R.; MCREATH, I.; SCHELLER, T. 1991. Granit6ide Tourto: um bat6lito subalcalino brasiliano no oeste do Rio Grande do Norte. In: SIMP. GEOL. NORDESTE, 14. Recife, 1991. Atas... Recife, SBG. p. 160-163.

GAMA, T., Jr.; COSTA, J.B.S.; HASUI, Y.; OLIVEIRA, MAF. 1990. A zona de cisalhamento de Grania e seu significado tectónico. In: CONGR. BRAS. GEOL, 36. Natal, 1990. Anais... Recife SBG. v. 5, p. 23302339

GAVA, A. \& LIMA, M.I.C. 1986. Evoluctio geologica policiclicn na regia de Floresta - PE. In: CONGR. BRAS. GEOL, 34, Goianiai 1986. Anaist. Goiânia, SBG, v. 2 , p. 793-809.

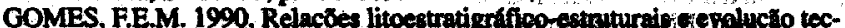
tónica na Faixa Riacho do Pontal - rogida de Paulintam (PI). In: CONGR. BRAS. GEOL, 36. Natal, 1990. Arrats. Recife, SB 63 w/. p. 2843-2857.

GUIMARÄES, I.P. \& SIIVA, A., PR 1990. Magmatismo in mivo shoshonitico na Faiza Pajed-Parafba: o complexo Bom Imdin on CONGR. BRAS. GEOL, 36. Natal, 1990. Amais.. Recife, SBG. v. 4, p. 1739-1751.

HACKSPACHER, P.C; VAN SCHMUS, W.R. DANTAS, E.L: 1990. Um embasamento transamazonico na Praxícia Bethorama. In: CONGR. BRAS. GEOL., 36. Natal, 1990. thats... Nocife, SBG: $4 \%$, p. 2683.2696 . 


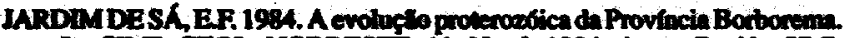
In: SIMP. GEOL NORDESTE, 11. Natal, 1984. Atas.. Recife, SBG. p. $297-316$.

JARDM DE SA, E.F. 1988. An update of the precambrian geology of Northent Bril In: INTERN. MEET. PROTEROZOIC GEOLTECTONICS HIOH-GRADE TERRANS. Do-IfeNigeria, 1988. Comerib. Ubl. UNESCONGCP, Univ. Ilo-lfe.

JARDM DE SR, EF. B BARBAIHO A.P. 1991. Novos dados sobre a deformacto tangexial na Faixa Serid6, NE do Brasil. In: SDMP. GEOL NORDESTE, 14. Recife, 1991. Alas... Recife, SBG. p. 296-299.

JARDM DE SÁ, R.P. \& CALHEIROS, M.EV. 1981. Eetrutures em nivel

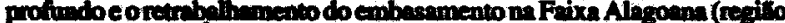
de Pilmein doe fidios). In: SIMP. GEOL NORDESTE, 10. Rocife, 1981. Alax. Recile, SBG. p. 351-360.

JARDM DESA, E. F. \& HACKSPACHER, P.C. 1980. Rocontrocimento esturwral ma berda norte do crition S\%o Francisoo. In: CONGR. BRAS. GEOL, 31. Canboric, 1980. Anais... Camboric SBG v. S p 2710-2731.

JARDMMDESA, E.F; KAWASHTA, K. MACBDO, MH.F.; SA, J.M. $1986 \mathrm{~b}$ Supracustais monociclicas no extremo ceste do Rio Grande do Norte. In: SIMP. GEOL NORDESTE, 12. Jolo Peesol, 1986. Atas... Recife, SBG. p. 62-74.

JARDMM DE SA, EF: LEGRAND JM: GALNDO AC.; SA, JM. HACKSPACHER, P.C. 1986c. Granitogenese bresiliena no Scrid6: o Macipo de Acari (RN). Reu Bras. Geoc, 16(1):95-105.

JARDM DE SA, EF. \& LETERRIER, J. 1990. Significado geodinfimico do plutoniemo pes betilinas me Provincie Borboreme. In: CONOR. BRAS. GEOL 36 Nent, 1990. Reswos. Recifs SBG. p. 299-300.

JARDIM DE SA, E.F; MACEDO, M.H.F; LEGRAND, JM.; MCREATH, I. GALINDO, A.C; SA, J.M. 1987. Proterozoics granitoids in e polycyclic setting: the Serido retion, NE Brwil. In: INTERN. SYMP. GRANITES AND ASSOC. MPNER ALZ Salvador, 1987. Extended Abstracts... Salvedor, SBG/SGM. p. 103-110.

JARDMM DE SA, E.F; MACEDO, M.H.F; TORRES, H.H.F; KAWASHTA K. 1988. Geochronology of inctuplutionics and the evolution of supracruenl belus in the Botbarema Province, NE Bravil. In: CONGR. LATINO-AMER GEO 7 Belcm 1983 Anis Belcin SBG p. $49-62$

JARDM DE SA, E.F; MORAES, J.A.C.; D'EL REY SHVA, LJ.H, 1986 Tectonica tungencial ma Faixa Servipane In: CONGR. BRAS. GEOL. 34. Goilnia, 1986. Anais... Goiluia, SBG. v. 3, p.1246-1259.

JARDM DE SA, EF.; SA, IM. MACEDO, M.H. 1990. Monocyclic and polycyclic suprecruetal belts in NE Brazil: comelations with the PanAfrican belt in Weat Africe In: ROCCI, G. \& DESCHAMPS, M. eds. Etudes Recentes Sur la Geologie de l'Afrique. Nancy, CIFEG. p. 169-173. (Col. Geol. Africaine 15).

JARDM DE SA, EF. \& SOUZA, LC. 1989. Relacoes cetratigraficas o a tectonica taneencial ma borda norte do Criton Sto Francisco. In: SIMP. NAC. ESTUDOS TECTONICOS., 2. Fortaleza, 1989. Atas.. Fortivers, SBG. p. 237-240.

LAGOERO, LE \& ALKMM, F.F 1991. A deformaclo compressional com fluxo laterimente confindo: um exemplo da sinclinel de irect, Chapada Dinmantine, Bahia In: SIMP. NAC. EST. TECT., 3. Rio Claro, 1991

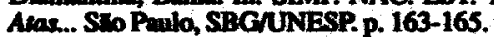

LEGRAND, J.M.; LIEGEOIS, J.P; DEUTSCH, S. 1991 . Datacto U/Fb e Rb

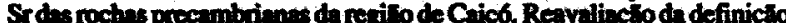
de vim embesmento eromemo. In: SIMP. GEOL. NORDESTE, 14. Recife, 1991. Atas.. Recife, SBG. p. 276-279.

LEGRAND, JM. \& SA, JM. 1986. Geotermometria, geobarometria c a zonecto metambefica do "sinforme de Cruzeta" - RN/Brasil. In CONGR. BRAS. GEOL, 34. Goiknia, 1986. Anais... Goiania, SBG. v. 4, p. $1407-1423$.

LESQUER, A.; BELTRÃO, J.F; ABREU, F.A.M. 1984. Proteroroic links between Northeast Bravil and West Africa: a p plate tectonic model based on gravity dan. Tecronophys. 110-2-26.

LETERRIER, J.; JARDM DE SA, E.F; MACEDO, M.HF.; AMARO, V.E 1990. Magmatic and geodynamic signature of the Brasilituno cycle plutonism in the Serids belt, NE Brazil. In: CONGR. BRAS. GEOL, 36. Nitel, 1991. Anais... Rocife, SBO. v. 4, p. 1640-1655.

LMA, E.S. 1987. Evolucto termo-barometrica das roches metapelficicas da regilo do Serido, Nordeste brasileiro. Rev Bras. Geoc., 17(3): 315-322.

LMA, MII.C; GAVA, A; FERNANDES, PE.C.,; PIRES, JL; SIGA, O. J.: ORTiz LR.C. 1986. Geologia e recurnos minerais da regiso de Flonest - PE In: SIMP. GEOL NORDESTE, 12. Jolo Pessoa, 1986 Alas.. Recife, SBG. p. 290-303.

MACEDO, M.H.F; JARDIM DE SA, E.F; PEUCAT, JJ.; SOUZA, ZS.; MARTIN, H. 1991. Avaliectio dos dados peocronológicos do Complexo Crico (RN) e san implickctes tectonices. In: SIMP. GEOL NORDESTE 14. Recife 1991. Atas... Recife SBG. p. 256-259.

MACEDO, M.H.; JARDM MEE SA; E.F; SA, JM. 1984. Detocoes Rb-Sr em ortogmaises e a idade do Grupo Serid6. In: SIMP. GEOL NORDESTE, 11. Nathl 1994. Atas.: Recifes S8G. p. 253-262

MACEDO MHF. JARDIM DE SK, EF. SATO $k$. KAWASHITA $K$ 1990. Dedos isotopicos preliminares de Nde Srua regilo do Serido (RNPB), e mas implicaptes tatonica. In: CONGR. BRAS. GEOL., 36. Netal, 1990. Restumas. Recife, SBG. p. 305-306.

MACEDO, M.FLF; MARTINS SA, J.; KAWASHITA, K 1988. A idade do Faixa Orós : dados preliminares. Rev Bras. Geoc., 18(3);362-368.
MARTW, H.; SOUZA, ZS.; FONSECA, V.P;; JARDMM DE SA, ER. 1990. Geochemintry of hightgrede metuplutonics: the Caico Complex, NEBrazil. In: CONGR. BRAS. GEOL,, 36. Natal, 1990. Resumas... Recife, SBG. p. 171.

MASCARENHAS, JF 1979. Evahupto Geosectonica do Precambriano do Estado da Bahia. Selvador, SME-BAMCPM. p. 55-165. (Geol. Rec. Min. Eetado da Bahia Textos B cieos 2)

MASCARENHAS, J.P. \& SA, J.H.S. 1982. Geological and metollogenic patterns in the Archean and early Proverozoic of Bahin state, eastem Bruxil. Rev. Bras. Geoc., 12(1-3):193-214.

MEDRIROS, H.; LETERRIER, J.; MARTIN, H.; JARDIM DE SA, E.P. 1991. Petrogufmica do granitolde "G2" a uudezte de Acu (Fsixa Serid6, RN). In: SIMP. GEOL. NORDESTE, 14. Re sife, 1991. Atas... Recife, SBG. p. 189-191.

MENDES, V.A. \& SILVA, M.A., F 198!1. PLGB, Cristdlia, Folha SC.24-V-BN, Texo e Mapas. Brasilia, DNPN VCPRM $120 \mathrm{p}$.

MORRIR A M.: MEDEIROS, WE : UNS, FA PL A C CHANIO CJ. USSAMA, N. 1989. Mapa gravimb́trico do Nordecte selentrional do Brasil e sua contribuichto 20 estudo da tectonica da trea. In: CONGR. SOC. BRAS. GEOR, 1. Rio de Janeiro, 1989. Anais... Rio de Janeiro, SBGf. v. 2, p. 531-537.

PESSOA R.R.; BRTTO NEVES, B.B.; KAWASHITA, K.; PESSOA, D.A.R.; FUCK, R.A. 1986. Contribuiçso do estudo da evoluçio geocronologica do macico de Trtia - CE. In: SIMP. GEOL. NORDESTE, 12. Jo Peseom, 1986. Alas... Recife, SBG. p. 75-93.

RAND, H.; SIAL, A.N.; BRTTO NEVES, B.B.; MANSO, V.V. 1980. Eetudo previmetrico e manotometrico do sistem de dobramentos Sergipano. In: CONGR BRAS. GEOL., 31. Camboriti, 1980. Anais... Camboría, SBG. v. 5, p. $2700-2708$.

SA, J.M. 1991. Evolution Geodynamique de la Ceinture Proterozoique d'Onss, Nond-Est du Bnstil. Nancy. I77 p. (Th'se Doctorat, U. Nancy I).

SA, J.M.; BERTRAND, J.M.; LETERRIER, J. 1991 . Evolution geodynamique a geochronologie (U-Pb, Rb-Sr a K-Ar) de la ceinture plisste d'Onos, NE du Brésil. C. R. Acad Sci. Paris, 313(ii):231-237.

SA, J.M.; BEZERRA, F.H.R.; MACEDO, M.H.F.; FERREIRA, R. 1988. Middle proterozoic rupracrustals and Brasilianso orogeny in the southeast Ceart state: a monocyclic evolution. In: CONGR. LATINO-AMER. GEOL, 7. Belem, 1988. Anais... Belem, SBG. p. 35-48.

SANIOS, CA \& SLVA, M.A. F 1990. PLGB, Riacho do Caboclo, Folha SC.24-V.A-VI, Testo e Mepas. Brastia, DNPMUCPRM. $113 \mathrm{p}$

SANTOS, EJ. BRITO NEVES, B.B. 1984. Provincia Borborema In: ALMEIDA, F.F.M. \& HASUI, Y. eds. O Pre-Cambriano do Brasil. S30 Paulo, Edgand Blucher. p. 123-186.

SANTOS, EJ.\& CALDASSO, A.LS. 1978. Sintesedos con hecimentoseensaio interpretativo da frea do Riacho do Pontal, Nordeste do Brasil. In: REUNIXOPREP.SMMP CRÁTONS. FRANCISCOEFAXXASMARGINAIS Salvador, 1977 . Amais... Salvador, SBG. Publ. Eep. 3, p. 399-426.

SANTOS, R.A. \& SOUZA, J.D. 1988. PLGB, Pinanhas, Folha SC.24-X-C-VI, Texso e Mapas. Braefili, DNPMCPRM. 154 p.

SIAL, AN. 1986. Granite types in Northeat Brazil: current knowledge. Rev. Bras. Geoc., 1G(1):54-72

SIAL, AN. 1987. Granitic rocks of Northeast Brazil. In: INTERN. SYMP. GRANITBS AND ASSOC. MINERALZ Salvador, 1987. Extended Abstracts... Salvador. SBG/SGM-BA. p. 61-69.

SIAL, A.N. \& FERREIRA, V.P. 1988. Brasiliano ace peralkaline plutonic rocks of the Central structural domain, NE Brazil. Rend. Soc. Ha. Min. Petrol, 43(2):307-342.

SILVA, A., F \& GUMMARÄES, 1.P. 1990. Geologin das roches vitrapotissicas da regillo de Salgueiro, PE. In: CONGR. BRAS. GEOL., 36. Natal, 1990. Anais... Recife, SBG. v. 4, p. 1752-1763.

SILVA, M. A, F. 1984. A faixa de dobramentos Pianc6: sintese do conhecimento enovas consideracotes. In: CONGR. BRAS. GEOL., 33. Rio de Janeiro, 1984. Arais... Rio de Janeiro, SBG. v. 7, p. 3337-3347.

SILVA MA F; BONFIM, LF.C.: SANTOS, R.A. 1978. A geossinclinal Sergipana: estratigrafia, estrutura e evoluctio. In: CONGR. BRAS. GEOL., 30. Recife, 1978. Anais... Recife, SBG. v. 6, p. 24642477.

SOUZA, L.C. \& JARDIM DE SA, E.F. 1989. O metamorfismo e a lectonica de noppes na ponglo margind sul da Faixa Riacho do Pontal. In: SMMP. NAC. EST. TECT., 2. Fortaleze, 1989. Atas... Fortaleza, SBG. p. $241-244$.

SOUZA, J.D. et al. 1979. Projeto Colomi: Geologia da Regiao do Medio Sab Froncisca. Brasflia DNPMNCPRM. (Reletório Final).

TOROUATO JR.F: SIDRM A.C.G.: MARANHX̃O CML. PARENTE C.V.; NOGUEIRA, J.A., Neto; ANDRADE J.F., F; SOUZA, J.V.; SOUZA, M.J.N.; ARTHAUD, M.H. 1989. Granitoides do Ceard. Regiso de Quixab-Solonopole. Reu. Geol UFCE, 2(1/2):1-143.

TROMPETTE, R. 1979. Les Dahomeyides au BÉnin, Togo et Ghana: une chaine de collision d'the pan-african. Rev. Géol. Dynamique et Géogr. Physique, 21(5):339-349.

WANDERLEY, A.A. 1990. PLGB, Monteiro, Folha SB.24-Z-D-IV, Texto e Mapas. Brasfia, DNPM/CPRM. 100 p.

MANUSCRITO A735 Recebido em 12 de maio de 1992 Revisão do Autor em 15 de setembro de 1992 Revisão aceita em 22 de outubro de 1992 